WellBeing International

WBI Studies Repository

$12-2004$

\title{
Size Matters: A Test of Boldness in Eight Populations of the Poeciliid Brachyraphis episcopi
}

Culum Brown

University of Edinburgh

Victoria Braithwaite

University of Edinburgh

Follow this and additional works at: https://www.wellbeingintlstudiesrepository.org/acwp_asie

Part of the Animal Studies Commons, Comparative Psychology Commons, and the Other Animal Sciences Commons

\section{Recommended Citation}

Brown, C., \& Braithwaite, V. A. (2004). Size matters: a test of boldness in eight populations of the poeciliid Brachyraphis episcopi. Animal Behaviour, 68(6), 1325-1329.

This material is brought to you for free and open access by WellBeing International. It has been accepted for inclusion by an authorized administrator of the WBI Studies Repository. For more information, please contact wbisr-info@wellbeingintl.org.

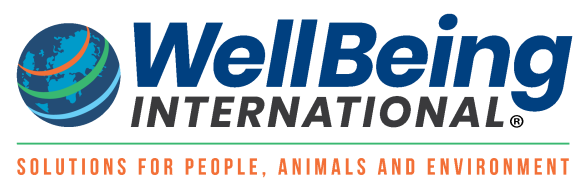




\title{
Size Matters: A Test of Boldness in Eight Populations of the Poeciliid Brachyraphis episcopi
}

Culum Brown and Victoria A. Braithwaite

University of Edinburgh

\begin{abstract}
Individual variation in behaviour within populations may be explained in part by demographics and longterm, stable individual psychological differences. We examined the relation between boldness (taken as the time to emerge from a shelter and explore a novel environment) and body size in eight populations of the poeciliid Brachyraphis episcopi originating from sites upstream and downstream of waterfalls in four rivers that run into the Panama Canal. The relation between body size and time to emerge from a shelter was positive, with larger fish taking longer to emerge. This relation differed between downstream and upstream sites, being significant in the upstream populations only. These results are best explained by a metabolic hypothesis whereby juvenile fish are compelled to emerge earlier in order to resume feeding. In the downstream sites this effect was slightly offset by the relatively greater predation threat for smaller fish, such that they delayed their emergence from cover. We discuss the underlying importance of variation in boldness and its effects on other behavioural and life history traits.
\end{abstract}

The study of individual variation in animal behaviour has become increasingly active over the last decade (Wilson 1998). Central to understanding this variance is the potential effect of consistent 'personality' traits, such as the boldness-shyness continuum (Wilson et al. 1994; Coleman \& Wilson 1998), differences in coping styles (Benus et al. 1991), and demographic variables such as sex, age and reproductive state.

The propensity to take risks (boldness) has implications for survival, reproduction and many other life history and behavioural traits (e.g. Budaev 1997a, b). Bold fish, for example, are more likely to explore novel objects, discover novel food sources or patches and stray from their normal home range (Wilson et al. 1993; Fraser et al. 2001). Bold minnows, Phoxinus phoxinus, inspect predators more often, show higher rates of skittering and forage more persistently in the face of predation threat than shy minnows (Murphy \& Pitcher 1997). Female guppies, Poecilia reticulata, prefer to mate with bolder males (Godin \& Dugatkin 1996), and bolder males are most likely to inspect approaching predators (Godin \& Davis 1995). Bold fish may also escalate fights with conspecifics in the presence of a predator (Brick \& Jakobsson 2002).

The propensity to take risks (boldness) has long been associated with an individual's nutritional state (Sih 1997), so it may also be indirectly influenced by demography. Hungry fish are more likely to take risks than satiated fish by emerging from shelters sooner to maximize foraging opportunities, but at the 
expense of increasing their exposure to predation. If boldness is affected by internal states and related demographic variables, then it is likely that individual boldness scores will vary from day to day or over the lifetime of an individual. As contexts change over an individual's lifetime so too might its degree of boldness. One potential axis of contextual change is variation caused by growth that results in differences in motivational states within an individual on an ontogenetic timescale.

In the banded killifish, Fundulus diaphanus, the time spent in a refuge after exposure to a model trout predator decreased with increasing body size suggesting that small killifish are more vulnerable to predation than larger killifish (Dowling \& Godin 2002). The reverse was true for a similar study involving sticklebacks, Gasterosteus aculeatus, that were exposed to a model kingfisher (Krause et al. 1998) suggesting that the type of threat may be important in determining emergence latencies. In two further studies of the killifish Rivulus hartii, Fraser et al. (2001) and Wilson et al. (1993) both found no relation between boldness and body size. Despite these conflicting results, there are compelling reasons to suspect that body size should be correlated with boldness. First, small fish are far more vulnerable to predation (reviewed in Sogard 1997) and therefore should be more wary in novel situations and emerge from shelter later than large fish (predation hypothesis). Second, juveniles have lower body fat reserves, faster metabolic rates and higher drag coefficients than adults and are therefore compelled to emerge from shelters and begin foraging sooner than larger fish (metabolic hypothesis; Wooton 1994; Krause et al. 1998; Skalski \& Gilliam 2002). These two hypotheses result in conflicting predictions with respect to the relation between body size and boldness. The first predicts a positive relation whereas the latter predicts a negative one. Thus, the degree of boldness displayed by an individual is likely to change with ontogeny, reflecting the perceived risk to the individual and its metabolic status.

Previous studies have considered variation in the time to emerge from a shelter in a single population of fish. The decision to emerge, however, should be influenced by a number of habitat variables, including predation pressure, foraging competition or food availability (Godin 1997; Sih 1997; Dowling \& Godin 2002). We investigated the tendency of eight populations of the poeciliid Brachyraphis episcopi, originating from sites above and below waterfalls, to emerge from a shelter and explore a novel environment (taken as an indicator of an individual's boldness, see Sneddon 2003). We predicted that fish from below falls (high-predation sites) would be less bold on average than fish from above falls (lowpredation sites), and therefore emerge from shelter later. Furthermore, we predicted the relation between body size and boldness would differ between upstream and downstream sites owing to different selection pressures operating in these regions.

\section{METHODS}

We collected eight populations of fish from four streams along the Pipeline Road near Gamboa, Panama (Table 1) under a permit issued by the National Authority for the Environment (ANAM). Since B. episcopi does not inhabit the Panama Canal and the rivers run directly into the canal, each represents an independent sample. In each river, we collected one population above a waterfall that represented a significant barrier to upstream fish movement. The distance between upstream and downstream sites was kept to a minimum to minimize genetic differentiation. In all cases, the distance between sites was less than $500 \mathrm{~m}$. Above the falls, the fish fauna is highly depauperate and is dominated by $B$. episcopi and the killifish $R$. brunneus. Below the falls, the fauna is primarily made up of members of the characin family as well as cichlids (Geophagus and Aequidens spp.), tigerfish (Haplies spp.) and other potential predators. Nevertheless, $B$. episcopi is present below the falls but in much lower abundance (Table 1). In many respects, the system and species involved mimic that of the well-studied Trinidadian guppy (Reznick \& Endler 1981). 
Table 1. The relative percentage of fish making up the fauna at each site

\begin{tabular}{|lccc|}
\hline River & Brachyraphis episcopi & Predatory fish & Other fish \\
\hline Rio Agua Salud & & & \\
Above falls & 99 & 0 & 1 \\
$\quad$ Below falls & 55 & 45 & 0 \\
Rio Macho & & 0 & 21 \\
$\quad$ Above falls & 79 & 54 & 9 \\
$\quad$ Below falls & 37 & & 11.5 \\
Rio Limbo & 86 & 2.5 & 15 \\
$\quad$ Above falls & 5 & 80 & 0 \\
Below falls & & & 6 \\
Quebrada Juan Grande & 99 & 1 & \\
$\quad$ Above falls & 16 & 78 & \\
Below falls & & &
\end{tabular}

Brachyraphis episcopi is a small (to $5 \mathrm{~cm}$ ) poeciliid that is an opportunistic omnivore feeding primarily on insects and fruit. Its general behavioural ecology is not well documented but it is clear that large females are territorial whereas smaller females tend to form loose shoals. Males roam as individuals and are highly aggressive towards one another. When threatened, all fish tend to hide rather than form schools and preliminary investigation suggests that there is no difference in schooling responses between upstream and downstream locations (unpublished data). Jennions \& Telford (2002) reported that reduced predation pressure on fish from upstream locations has a significant flow-on effect on their life history strategies. Upstream (low-predation) fish reach a much larger size and tend to mature later than fish from downstream (high-predation) sites. These data are similar to those for other Brachyraphis species (Reznick et al. 1993) and poeciliids in general.

Approximately $40 \mathrm{~B}$. episcopi were collected from each site using seine nets, brought into a laboratory and transferred to eight housing aquaria $(58 \times 54 \mathrm{~cm})$. Males and females were housed together. Each housing aquarium contained gravel obtained from the appropriate rivers and a standard corner filter. Water was maintained at $15 \mathrm{~cm}$ depth. Water temperature was controlled by ambient air temperature but it remained at approximately $25^{\circ} \mathrm{C}$. Lighting consisted of twin overhead fluorescent tubes on a $12: 12 \mathrm{~h}$ light:dark cycle to mimic natural light patterns for the time of year (late July). The fish were fed standard flake food twice a day (morning and evening) except on the day of testing when they were fed after the experiment.

Fish were tested approximately 9 days after capture. A single female was chosen at random from a population and placed into the test arena. Only females longer than $2 \mathrm{~cm}$ were tested. Fish smaller than 2 $\mathrm{cm}$ are immature and therefore cannot be sexed and males are relatively rare. The test arena consisted of a tank of identical dimensions to the housing tanks, but with shallower water $(8 \mathrm{~cm})$ and no gravel. In one corner, a blue bucket $(20 \mathrm{~cm}$ diameter) was positioned upside down to form a shelter. A small hole $(3 \times 3 \mathrm{~cm})$ cut in the bucket allowed the fish to exit the shelter and explore the rest of the arena. Within the bucket, a clear plastic cylinder of $15 \mathrm{~cm}$ diameter allowed the experimenter to constrain the test fish during a 5-min settling period. After this period, a remote pulley lifted the cylinder clear of the water and the fish was free to emerge from the shelter and explore the test arena. The observer was able to watch the behaviour of the test subject remotely on a computer monitor connected by firewire (Belkin FireWire 
cable IEEE 1394) to a digital camera mounted over the test arena. We recorded the time until the fish's head emerged from the shelter. Fish that failed to emerge within $10 \mathrm{~min}$ of the bottle being lifted were given the maximum score of $600 \mathrm{~s}$ (only 9 of 160 fish tested failed to emerge: five from regions of high predation and four from low-predation areas). After emerging from the shelter the fish were allowed to swim freely around the test arena and explore it before being netted and measured (standard length \pm 1 $\mathrm{mm}$ ). No fish was tested more than once. We tested 20 fish from each of the eight locations. After the experiment, the fish were transported to the University of Edinburgh where they were incorporated into a breeding programme for ongoing studies.

Data on the time to emerge from shelter were log transformed and examined for a relation with standard length using regression analysis. A test of parallelism as a post hoc analysis under an analysis of covariance (ANCOVA) was then used to determine whether the gradient of the two regression slopes differed significantly. An ANCOVA was further used to examine the effects of location (upstream and downstream) and stream identity as independent fixed variables, with log (time to emerge) as the dependent variable and standard length as the covariate.

\section{RESULTS}

Regression analysis revealed a significant positive relation between standard length and the time the fish took to emerge from the shelter $\left(F_{1,158}=15.09, P=0.0002\right)$. Smaller fish emerged from the shelter sooner than larger fish, which supports the metabolic hypothesis. We further examined the relation by investigating the data from high-predation and low-predation sites independently. This analysis revealed that the relation between standard length and time to emerge from the shelter for fish from the highpredation sites was positive but not significant $\left(F_{1,78}=1.70, P=0.20\right)$. In contrast, the fish from the lowpredation sites showed a highly significant positive relation $\left(F_{1,78}=17.41, P<0.0001\right.$; Fig. 1$)$. A post hoc test of parallelism suggested that the gradients of these two regression lines were not significantly different $\left(F_{1,150}=0.54, P=0.46\right)$.

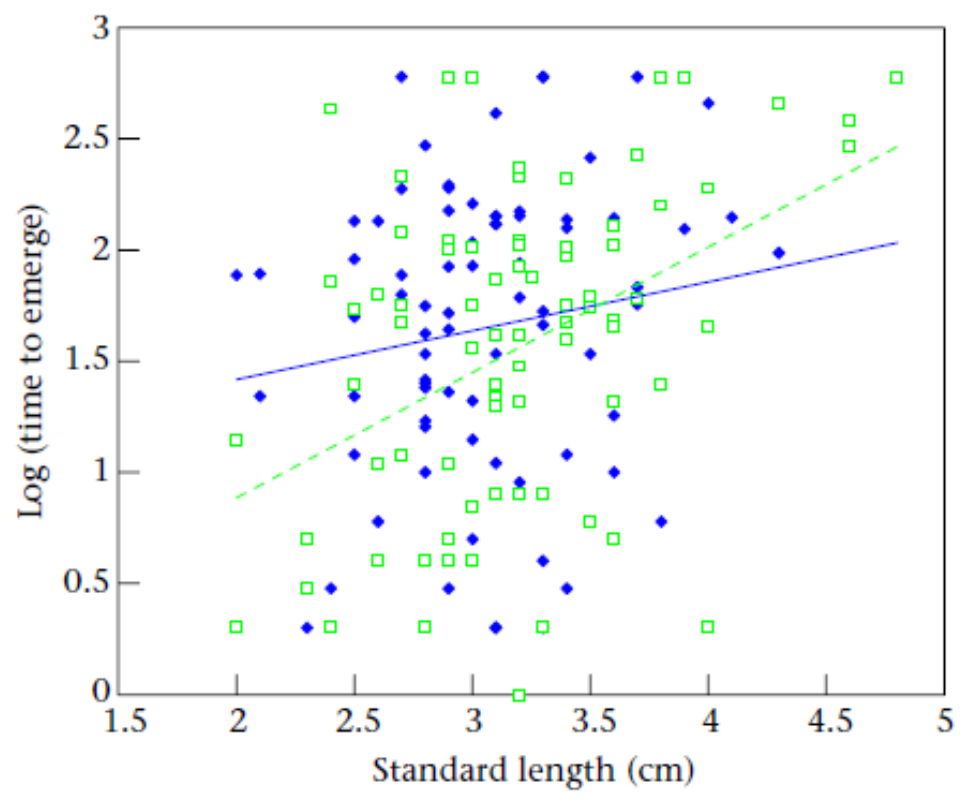

Figure 1. The relation between standard length and time to emerge from the shelter for fish from upstream ( $\square$; - - -; low-predation) and downstream ( ; d; high-predation) sites. Regressions: upstream: $y=0.5633 x$ 0.2402 ; downstream: $y=0.2194 x+0.9789$. 
Regression analysis revealed a significant positive relation between standard length and the time the fish took to emerge from the shelter $\left(F_{1,158}=15.09, P=0.0002\right)$. Smaller fish emerged from the shelter sooner than larger fish, which supports the metabolic hypothesis. We further examined the relation by investigating the data from high-predation and low-predation sites independently. This analysis revealed that the relation between standard length and time to emerge from the shelter for fish from the highpredation sites was positive but not significant $\left(F_{1,78}=1.70, P=0.20\right)$. In contrast, the fish from the lowpredation sites showed a highly significant positive relation $\left(F_{1,78}=17.41, P<0.0001\right.$; Fig. 1$)$. A post hoc test of parallelism suggested that the gradients of these two regression lines were not significantly different $\left(F_{1,150}=0.54, P=0.46\right)$.

The ANCOVA revealed a significant effect of stream $\left(F_{3,151}=4.91, P=0.003\right)$ but no difference between upstream and downstream sites $\left(F_{1,151}=2.08, P=0.15\right)$. There was a significant interaction between the two factors $\left(F_{3,151}=3.92, P=0.01\right)$. Post hoc analysis (Fisher's Protected Least Significant Difference, PLSD) revealed that fish from the Rio Agua Salud (AS) emerged from the refuge significantly faster than fish from all other rivers. The time to emerge from the refuge for fish from the Rio Limbo (RL), Quebrada Juan Grande (QJG) and Rio Macho (RM) were not significantly different from one another. Once standard length had been controlled for, fish from the RM upstream site emerged more rapidly than RM downstream fish, whereas the reverse was true for QJG (Fig. 2). Fish from upstream areas of both the AS and the RL tended to emerge earlier than downstream fish but these differences were not significant (Fig. 2).

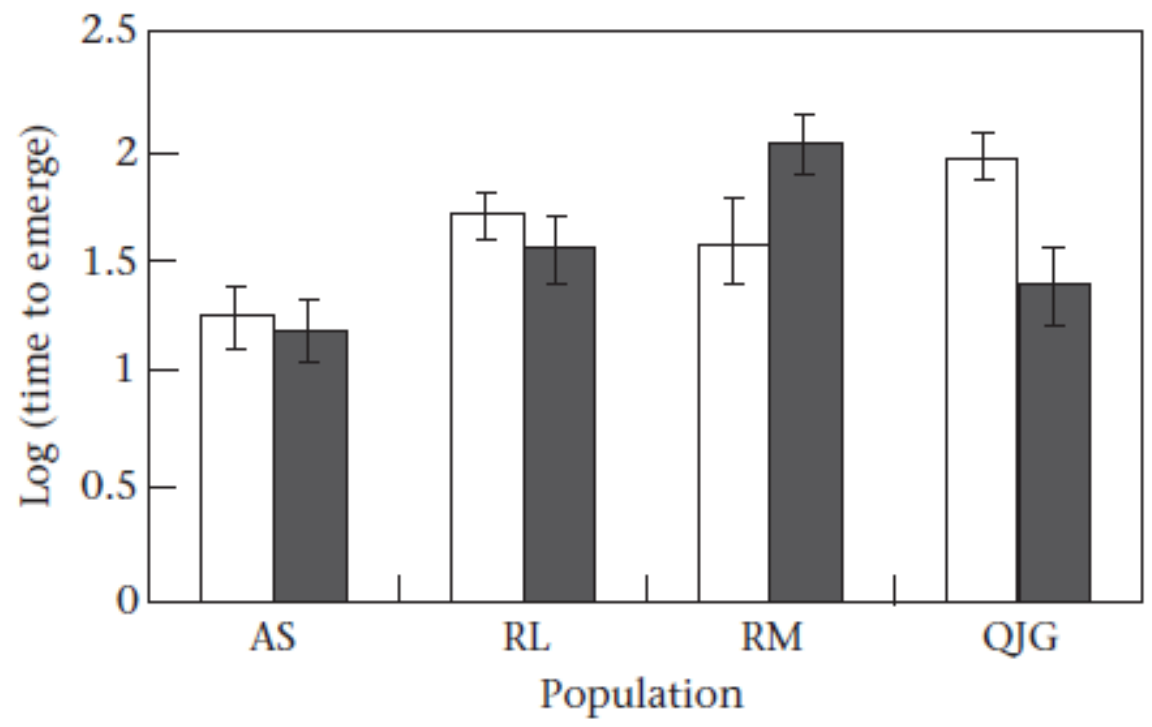

Figure 2. The mean \pm SE time to emerge from the shelter adjusted for standard length for fish from downstream ( $\square$; high-predation) and upstream ( $\square$; low-predation) sites in each of the four streams. AS: Rio Aqua Salud; RL: Rio Limbo; RM: Rio Macho; QJG: Quebrada Juan Grande.

The standard length of test fish differed between the four streams $\left(F_{3,152}=4.27, P<0.01\right)$. There was a marginal difference between upstream and downstream sites $\left(F_{1,152}=3.05, P=0.08\right)$. Fish from highpredation sites tended to be smaller than fish from low-predation sites. Post hoc analysis (Fisher's PLSD) revealed that fish from RM were significantly larger than fish from all other rivers (versus QJG, RL and 
AS: $P=0.013,0.001$ and 0.006 , respectively). There were no significant differences in the standard length of the fish at any of the other sites.

\section{DISCUSSION}

The boldness scores of $B$. episcopi (as defined as the time to emerge from a shelter) were overwhelmingly affected by their body size. As predicted by the metabolic hypothesis, whereby juvenile fish have a higher metabolic rate and fewer body fat reserves, smaller fish emerged from shelter sooner than larger fish. It is well established that metabolic rate increases with the natural log of body mass, but metabolic rate per $\mathrm{g}$ of body weight decreases with increasing body size. In teleost fish, the relation between the natural log of resting oxygen consumption and the natural log of body mass gives a scaling exponent of 0.79 (Clarke \& Johnston 1999). As in all other animals, metabolic rate per $\mathrm{g}$ of body mass and body size has a negative exponential allometric relation in fish. It is likely, therefore, that small fish are compelled to emerge sooner than larger fish regardless of the level of predation pressure at each location owing to energy constraints. Although the effect of body size on boldness did not differ significantly between upstream and downstream sites, this relation was far stronger in the upstream localities where there are fewer predators. In the downstream locations there may be a trade-off between the direct effects of predation pressure and the metabolic requirements of juveniles, thus flattening the regression by forcing juveniles to stay in the refuge for longer (Fig. 1).

Alternatively, since age is correlated with standard length, older fish may be more wary in general, having learnt from experience that early emergence increases the threat of predation. An alternative hypothesis is that all bold fish have long since been killed by predators and only the more wary fish survive to old age. Although these hypotheses seem unlikely, it should be borne in mind that there is little evidence to suggest that food deprivation leads to earlier emergence times in fish (e.g. Dowling \& Godin 2002). Nevertheless, activity levels do increase early on during food deprivation periods in cyprinids (Wieser et al. 1992) suggesting a shift to increased foraging behaviour.

Once body length was controlled for, differences in emergence times between upstream and downstream sites varied significantly between streams. In one stream, upstream fish emerged earlier than downstream fish, whereas in another the reverse was true. Fauna surveys conducted at each location suggest that the predation pressure is probably greatest in the Rio Limbo and the Quebrada Juan Grande downstream sites and in these locations $B$. episcopi comprises only a small proportion of the total fish diversity (Table 1). These differences do not translate directly into the emergence behaviour of the fish since there is no relation between the relative abundance of predators and the time to emerge at each site. Perhaps equally importantly, the Rio Limbo and in particular the Rio Macho upstream sites have a significant number of heterospecific competitors in the form of the killifish $R$. brunneus. Upstream sites may be relatively poor sites in terms of productivity (Reznick et al. 2001) and therefore competition may play an important role in shaping the behaviour of the fish in these regions. We suspect that foraging competition and food availability may be just as important as predation pressure in determining the time to emerge from shelter, but these factors are difficult to quantify in the wild.

In the present study there may be other, as yet unexplored, ecological variables such as varying degrees of juvenile cannibalism at each site that may result in varying levels of boldness. For instance, Tully \& Huntingford (1987) found that boldness was partially heritable in sticklebacks but was also affected by the level of chasing by fathers. Wilson et al. (1994) suggested that the natural environment creates and maintains individual differences in boldness, but prolonged periods of captivity may cause behavioural convergence. It is unlikely that the brief period of captivity altered the behaviour of the fish in this instance. Nevertheless, there may be differences in the way the fish respond to the handling stress and 
the manner in which they settle in the laboratory. Testing the procedure in the field would be one way of overcoming some of these unknown variables.

In conclusion, balancing predation risk with foraging rate is a well-studied phenomenon in fish (reviewed in Lima \& Dill 1990). There are numerous models examining whether juvenile fish choose habitats that maximize growth rate or minimize predation risk or whether they attempt to minimize the ratio of risk to growth (Dahlgren \& Eggleston 2000; Skalski \& Gilliam 2002). Our data suggest that small fish are driven to emerge from hiding to maximize food intake and thus growth rate rather than to reduce predation pressure. While there is some evidence that the relation is influenced by environmental variables such as foraging competition and predation pressure, this still requires further investigation.

\section{Acknowledgments}

This research was funded by NERC grant number (NER/A/S/01/00608). We thank the Smithsonian Tropical Research Institute for their continued support and, in particular, Biff Birmingham for his help in identifying fish species. We also thank Michael Jennions for his aid in identifying field sites and for comments on the manuscript. Finally, thanks to Felicity Brown for all her help collecting fish and other field data.

\section{References}

Benus, R., Bohus, B., Koolhas, J. \& van Oortmerssen, G. 1991. Heritable variation for aggression as a reflection of individual coping strategies. Experientia, 47, 1008-1019.

Brick, O. \& Jakobsson, S. 2002. Individual variation in risk taking: the effect of a predatory threat on fighting behavior in Nannacara anomala. Behavioral Ecology, 13, 439-442.

Budaev, S. V. 1997a. Alternative styles in the European wrasse, Symphodus ocellatus: boldness-related schooling tendency. Environmental Biology of Fishes, 49,71-78.doi:10.1023/A:1007380212475.

Budaev, S. V. 1997b. 'Personality' in the guppy (Poecilia reticulata): a correlational study of exploratory behaviour and social tendency. Journal of Comparative Psychology, 111, 399-411.

Clarke, A. \& Johnston, N. M. 1999. Scaling of metabolic rate with body mass and temperature in teleost fish. Journal of Animal Ecology, 68, 893-905. doi:10.1046/j.1365-2656.1999.00337.x.

Coleman, K. \& Wilson, D. S. 1998. Shyness and boldness in pumpkinseed sunfish: individual differences are context-specific. Animal Behaviour, 56, 927-936.

Dahlgren, C. P. \& Eggleston, D. B. 2000. Ecological processes underlying ontogenetic habitat shifts in a coral reef fish. Ecology, 81, 2227-2240.

Dowling, L. M. \& Godin, J. G. J. 2002. Refuge use in a killifish: influence of body size and nutritional state. Canadian Journal of Zoology, 80, 782-788.

Fraser, D. F., Gilliam, J. F., Daley, M. J., Le, A. N. \& Skalsk, G. T. 2001. Explaining leptokurtic movement distributions: intrapopulation variation in boldness and exploration. American Naturalist, 158, 124-135.

Godin, J. G. J. 1997. Evading predators. In: Behavoural Ecology of Teleost Fishes (Ed. by J. G. J. Godin), pp. 191-236. Oxford: Oxford University Press.

Godin, J. G. J. \& Davis, S. A. 1995. Who dares, benefits: predator approach behavior in the guppy (Poecilia reticulata) deters predator pursuit. Proceedings of the Royal Society of London, Series B, 259, 193-200. 
Godin, J. G. J. \& Dugatkin, L. A. 1996. Female mating preference for bold males in the guppy, Poecilia reticulata. Procedings of the National Academy of Sciences, U.S.A., 93, 10262-10267.

Jennions, M. D. \& Telford, S. R. 2002. Life-history phenotypes in populations of Brachyrhaphis episcopi (Poeciliidae) with different predator communities. Oecologia, 132, 44-50. doi:10.1007/s00442002-0942-4.

Krause, J., Loader, S. P., McDermott, J. \& Ruxton, G. D. 1998. Refuge use by fish as a function of bodylength-related metabolic expenditure and predation risk. Proceedings of the Royal Society of London, Series B, 265, 2373-2379.

Lima, S. L. \& Dill, L. M. 1990. Behavioral decisions made under the risk of predation: a review and prospectus. Canadian Journal of Zoology, 68, 619-640.

Murphy, K. E. \& Pitcher, T. J. 1997. Predator attack motivation influences the inspection behaviour of European minnows. Journal of Fish Biology, 50, 407-417. doi:10.1006/jfbi.1996.0301.

Reznick, D. \& Endler, J. A. 1981. The impact of predation on life history evolution in Trinidadian guppies (Poecilia reticulata). Evolution, 36, 160-177.

Reznick, D., Meyer, A. \& Frear, D. 1993. Life-history of Brachyraphis rhabdophora (Pisces, Poeciliidae). Copeia, 1993, 103-111.

Reznick, D., Butler, M. J. \& Rodd, H. 2001. Life-history evolution in guppies. VII. The comparative ecology of high and low predation environments. American Naturalist, 157, 126-140.

Sih, A. 1997. To hide or not to hide? Refuge use in a fluctuating environment. Trends in Ecology and Evolution, 12, 375-376. doi:10.1016/S0169-5347(97)87376-4.

Skalski, G. T. \& Gilliam, J. F. 2002. Feeding under predation hazard: testing models of adaptive behavior with stream fish. American Naturalist, 160, 158-172.

Sneddon, L. U. 2003. The bold and the shy: individual differences in rainbow trout. Journal of Fish Biology, 62, 971-975. doi:10.1046/j.1095-8649.2003.00084.x.

Sogard, S. M. 1997. Size-selective mortality in the juvenile stage of teleost fishes: a review. Bulletin of Marine Science, 60, 1129-1157.

Tully, J. J. \& Huntingford, F. A. 1987. Parental care and the development of adaptive variation in antipredator responses in sticklebacks. Animal Behaviour, 35, 1570-1572.

Wieser, W., Krummschnabel, G. \& Ojwang-Okwor, J. P. 1992. The energetics of starvation and growth after refeeding in juveniles of three cyprinid species. Environmental Biology of Fishes, 33, 63-71.

Wilson, D. S. 1998. Adaptive individual differences within single populations. Philisophical Transactions of the Royal Society of London, Series B, 353, 199-205.

Wilson, D. S., Coleman, K., Clark, A. B. \& Biederman, L. 1993. Shy bold continuum in pumpkinseed sunfish (Lepomis gibbosus): an ecological study of a psychological trait. Journal Of Comparative Psychology, 107, 250-260.

Wilson, D. S., Clark, A. B., Coleman, K. \& Dearstyne, T. 1994. Shyness and boldness in humans and other animals. Trends in Ecology and Evolution, 9, 442-446. doi:10.1016/0169-5347(94)90134-1.

Wooton, R. J. 1994. Energy allocation in the threespine stickleback. In: The Evolutionary Biology of the Threespine Stickleback (Ed. by M. A. Bell \& S. A. Foster), pp. 116-143. Oxford: Oxford University Press. 